\title{
Household Energy Insecurity and COVID-19 Have Independent and Synergistic Health Effects on Vulnerable Populations
}

\section{OPEN ACCESS}

Edited by:

Reginald Quansah,

University of Ghana, Ghana

Reviewed by:

Emily Nix,

University of Liverpool,

United Kingdom

Kwaku Poku Asante,

Kintampo Health Research

Centre, Ghana

Rachel Anderson De Cuevas,

University of Liverpool,

United Kingdom

*Correspondence:

Godfred O. Boateng

godfred.boateng@uta.edu

Specialty section:

This article was submitted to Environmental health and Exposome,

a section of the journal

Frontiers in Public Health

Received: 23 September 2020 Accepted: 22 December 2020 Published: 21 January 2021

Citation:

Boateng GO, Phipps LM, Smith LE and Armah FA (2021) Household Energy Insecurity and COVID-19 Have Independent and Synergistic Health

Effects on Vulnerable Populations.

Front. Public Health 8:609608.

doi: 10.3389/fpubh.2020.609608

\section{Godfred O. Boateng ${ }^{1 *}$, Laura M. Phipps ${ }^{1}$, Laura E. Smith ${ }^{2}$ and Frederick A. Armah ${ }^{3}$ \\ ${ }^{1}$ Department of Kinesiology, College of Nursing and Health Innovations, The University of Texas at Arlington, Arlington, TX, United States, ${ }^{2}$ Department of Epidemiology and Environmental Health, School of Public Health and Health Professions, University at Buffalo, Buffalo, NY, United States, ${ }^{3}$ Department of Environmental Science, University of Cape Coast, Cape Coast, Ghana}

Household energy insecurity (HEINS) is detrimental to the health of the poor and most vulnerable in resource-poor settings. However, this effect amidst the COVID-19 pandemic and the uneven implementation of restrictions can create a synergistic burden of diseases and health risks for the most vulnerable in low- and middle-income countries, exacerbating the health equity gap. Based on existing literature, this paper develops three key arguments: (1) COVID-19 increases the health risks of energy insecurity; (2) HEINS increases the risk of spreading COVID-19; and (3) the co-occurrence of COVID-19 and HEINS will have compounding health effects. These arguments make context-specific interventions, rather than a generic global health approach without recourse to existing vulnerabilities critical in reducing the spread of COVID-19 and mitigating the effects of energy insecurity. Targeted international efforts aimed at financing and supporting resource security, effective testing, contact tracing, and the equitable distribution of vaccines and personal protective equipment have the potential to ameliorate the synergistic effects of HEINS and COVID-19 in resource-poor countries.

Keywords: COVID-19, energy insecurity, household, health effects, health inequity, vulnerable populations

\section{INTRODUCTION}

Energy insecurity, the lack of access to adequate, affordable, reliable, acceptable, and clean sources of energy for a healthy and sustainable livelihood, has detrimental consequences for many households in developing countries $(1,2)$ and low-income settings in the developed world (3). Household energy insecurity (HEINS), like other resource insecurities such as food and water insecurity, can be symptomatic of broader economic disadvantages and social inequalities faced by the poor. The effects of energy insecurity at the household level are numerous and can pose psychosocial (e.g., stress, anxiety), economic (e.g., decrease in income generating activities), disease (e.g., diarrhea, respiratory infections), and nutritional burdens (e.g., dietary restrictions, food insecurity) on the most vulnerable $(1,3,4)$. These burdens are hypothesized to worsen as a result of the coronavirus disease (COVID-19), which is caused by severe acute respiratory syndrome coronavirus 2 (SARS-CoV-2), due to the uneven implementation of restrictive health mandates. Measures put forth by the World Health Organization (WHO) that focus on total lockdowns (5), in particular, may increase the disease burden associated with energy insecurity at the household 
level. This supports the fact that a generic public health approach to mitigating infectious disease may not be effective in certain settings (6). HEINS can also increase the spread of COVID19 in most low-income households due to the need for their members to leave home to collect household fuels, food, and water resources. The co-occurrence of COVID-19 and HEINS could amplify the psychosocial and disease burdens experienced by low-income households and further widen the health equity gap. This paper aims to draw out the independent effects of HEINS and COVID-19 and discuss their potential syndemic effects on households.

\section{COVID-19 INCREASES THE HEALTH RISKS OF ENERGY INSECURITY}

COVID-19 has proven difficult to control as effective and safe vaccines are still out of reach of the very poor (7, 8). By the end of June 2020, WHO reported almost 10 million cases of infection and half a million deaths (9). The WHO report suggested the cases were doubling about every 6 weeks, with sub-Saharan Africa (SSA) expected to be the next epicenter of the disease. WHO cautions national and local authorities to balance interventions when addressing the health impact of COVID-19 citing unintended consequences caused by uneven interventions, such as loss of income or the interruption of essential services (9). Measures aimed at limiting the spread of the virus from one area to another include, among other things, limiting the movement of persons locally or nationally. These preventive measures, however, may have unintended consequences (5). While there is evidence to show that sheltering-in-place reduces the risk of COVID-19 infection, the implementation of this generic approach, which has taken the form of curfews and partial lockdowns in some LMICs, without recourse to existing vulnerabilities has created worse conditions for many households.

Aside from psychosocial effects such as anxiety, stress, depression, frustration, and the increased tendency to attempt or commit suicide $(10,11)$, having to stay indoors has increased energy insecurity for many households in sub-Saharan Africa. The World Energy Outlook 2020 report indicates the pandemic has reversed progress made in sub-Saharan Africa, with the number of those lacking electricity increasing by 13 million people, or $2 \%$, from last year to more than 590 million in 2020 (12). A number of factors has led to this increase. Primarily, utilities that deliver clean energy now face serious financial constraints, African governments have now been compelled to shift their immediate priorities to securing the health of their populations, and there is limited financial aid available to expand and improve electricity infrastructure. Additionally, the International Energy Agency estimates that the rise in poverty levels worldwide has made basic electricity services unaffordable for over 100 million people with electricity connections, resulting

Abbreviations: COVID-19, Coronavirus diseases; HEINS, household energy insecurity; IEA, International Energy Agency; LMIC, low-and middle-income countries; SARS-CoV-2, severe acute respiratory syndrome coronavirus 2; SSA, sub-Sahara Africa; WHO, World Health Organization. in households reverting to more polluting, and inefficient sources of energy (12). In 2017, the International Energy Agency report on transitions from poverty to prosperity showed that about 2.8 billion people lacked access to clean cooking, with 2.5 billion relying on the traditional use of solid biomass (13). This number is estimated to be increasing due to the COVID-19 pandemic as more households' resort to solid fuels. Solid biomass is sourced from materials such as wood, straws, agricultural residue, process waste (sawdust), algae, and seaweed. The affordability and availability of biomass have made it a primary source of cooking fuel for most low-income households in developing countries in Asia and sub-Saharan Africa. However, social and health interventions such as total or partial lockdown aimed at reducing the spread of COVID-19 has also hampered access to energy resources and other developmental programs to secure clean energy, resulting in debilitating consequences on the health of many low-income households.

The indirect and social effects of the pandemic are predicted to have worse consequences on women than men; in fact, the United Nations Population Fund warns that as nations implement shelter-in-place measures, women are more likely to bear higher proportions of the domestic burden (14). In this context, women who cook with solid fuels indoors are at higher risk of respiratory infections during the lock down as they are increasingly exposed to poisonous gases from incomplete fuel combustion (15). Households that are energy insecure may also be in danger of food poisoning and gastrointestinal infection due to the consumption of contaminated food and water that could not be sufficiently heated (1). Furthermore, the absence of cooking fuel in households whose main food sources are staples that require cooking could lead to hunger caused by lower caloric intake, malnutrition, and associated health complications. It could also lead to an increase in the anxiety, stress, and frustrations associated with energy insecurity (1). Additionally, energy insecurity may lead to the termination of income-generating activities (e.g., dressmaking, hairdressing, and commercial cooking) for households that depend on energy for sustainable livelihood. Consequently, minimizing the transmission of COVID-19 in developing countries calls for specific interventions and smart policies that consider the complex conditions in which people live.

\section{ENERGY INSECURITY INCREASES THE RISK OF SPREADING COVID-19}

A bidirectional relationship is hypothesized to exist between energy insecurity and the spread of COVID-19. For instance, whereas energy-secure households have ready access to energy and may have the capacity to remain home when required, members of energy-insecure households in developing countries often must leave home to gather firewood or other resources for energy and may consequently have a higher risk of being exposed to the coronavirus (16). This may further be exacerbated by the depletion of existing fuel stalks as entire households' shelter-in-place and the frequency of cooking increases. We further contend that energy insecurity could impede adherence 
to guidelines and increase the spread of COVID-19 not only in developing countries but also in low-income settings within developed countries.

Economic deprivation in these low-income settings compounded by poor housing worsens the effects of energy insecurity leading to an increased risk of exposure to COVID-19. Hernández (3) and Hernández et al. (17) report that poor housing quality and lack of proper maintenance leads to poor insulation, limited ventilation, and the malfunctioning of heating and cooling systems. Sheltering-in-place in such conditions further exacerbates the health risks associated with poor housing, such that in the United States, counties with a higher percentage of households with poor housing have been found to have a higher incidence of morbidity and mortality associated with COVID-19 (18). Second, it means low-income households will be less likely to adhere to guidelines supporting social distancing measures. Leaving the house for part or the entire day might mitigate the effects of energy insecurity within the house but will increase the risk of COVID-19 infection for such populations. The lack of cooling systems in households amidst humid temperature and heat waves can mean an increase in visits to cooling centers, which are commonly implemented in hot regions within developed countries to provide a safe location to low-income populations from heat-related morbidity and mortality (19). Daanen et al. (20) assert that going to public cool areas in the hot season interferes with stay -athome recommendations to reduce the spread of the virus. For households bound by stay-at-home orders, constraints on movement mean energy-insecure households in cold climates may have to continue to live in the cold with an increased risk of hypothermia, while those that live in hot and humid climates have an increased risk of hyperthermia. The need for energy security may also necessitate some low-income household members to leave their housing to seek employment, increasing their risk of infection. These findings from prior studies call for an investigation into how poor housing and energy insecurity may be exacerbating the spread of COVID-19 infections among low-income households and increasing the health equity gap.

\section{THE SYNDEMIC EFFECTS OF COVID-19 AND ENERGY INSECURITY}

Syndemic theory posits that diseases cluster due to the interaction between social, environmental or biological, and political factors, which have compounding effects on each other (21). Using this framework, it is possible to see the co-occurrence of COVID-19 and energy insecurity exacerbating independent effects on each other and compounding the health effects associated with these biological and social forces. Thus, it is possible to see a significant increase in morbidity and mortality where COVID-19 interacts with social determinants of health. Household energy insecurity can result in low-income households burning biomass for heat and cooking, leading to household air pollution and subsequent respiratory diseases (COPD), acute lower respiratory infections in children and lung diseases in adults (22). In developed countries, energy insecurity at the household level can result in alternative heating behaviors such as using ovens to burn trash and turning on space heaters (e.g., wood stoves) and other heating equipment (e.g., fireplaces/chimneys, central heat, water heaters, and heat lamps) (23). The use of such heating fires has been found to be the leading cause of home fires and responsible for $86 \%$ of deaths and $78 \%$ of injuries $(23,24)$. Similarly, COVID19 has been found to increase the risk of lung complications such as pneumonia, acute respiratory distress syndrome, and sepsis. In both co-occurring events, symptoms such as shortness of breath, fever, and cough are common. Therefore, we argue that the occurrence of COVID-19 with HEINS-related diseases will increase adverse health effects for such households. This positions households in LMICs at a much higher risk of death from the disease than those in the developed countries. Secondly, dealing with energy insecurity and a total lockdown in the bid to prevent the spread of COVID-19 can decrease household income available for electricity or wood fuel and exacerbate the effects of energy insecurity (25). The syndemic effects of a pandemic and energy insecurity can subject the poorest and most vulnerable populations to both indirect health effects (discontinuation of essential health services, economic fall-out, social isolation) and to the disease itself, due to increased exposure (i.e., lack of hygiene, sanitation, ventilation, and preventive measures) and the presence of underlying conditions (25). In this context, both biological and socio-economic forces create not just a double burden, but a multiple burden of diseases on the most vulnerable in society, exacerbating the health equity gap. An in-depth investigation is needed to provide evidence of these syndemic effects and the associated health outcomes.

\section{DISCUSSION AND IMPLICATIONS}

This paper advances arguments pertaining to the independent effects of household energy insecurity and COVID-19 and their synergistic effects on vulnerable populations in poor resource settings. Although these propositions call for additional research, they have implications for the current approach implemented in low-income countries, which must prevent the spread of COVID-19 while mitigating the adverse effects of HEINS. The fact that the majority of households in poor resource settings do not have in-house access to energy resources suggests that broad preventive measures by WHO might not be entirely effective in developing countries within Asia or SSA, making countries in these two geographic areas highly vulnerable to rapid intracountry spread of COVID-19. With WHO predicting SSA as the next epicenter, it is important for global health experts, WHO and African leaders to develop context-specific interventions that also address the challenges intrinsic to HEINS. In addition, as safe COVID-19 vaccines become available, it is critical that countries in poor resource settings are supported by the international community to procure these vaccines for their populations. Indeed, adherence to a global equitable access to COVID19 vaccines may be one of the many pathways to improving resource security for the poor. Targeted international efforts aimed at financing and supporting resource security (energy, water, and food resources), effective testing, contact tracing, and 
the equitable distribution of vaccines and personal protective equipment have the potential to ameliorate the synergistic effects of HEINS and COVID-19. Next, we echo suggestions made by Dahab et al. (26) that in low-income countries, time-limited movement restrictions should be considered primarily as an opportunity to develop sustainable and resource appropriate mitigation strategies. We add that resources essential to daily living and survival should be made available and accessible in poor resource settings. Finally, the compounding effects of COVID-19 and energy insecurity have the potential to adversely affect the health of vulnerable populations, mandating the need for a more inclusive and proactive approach in dealing with the spread of COVID-19 in LMICs.

\section{DATA AVAILABILITY STATEMENT}

The original contributions presented in the study are included in the article/supplementary material. Further inquiries can be directed to the corresponding author.

\section{REFERENCES}

1. Boateng GO, Balogun MR, Dada FO, Armah FA. Household energy insecurity: dimensions and consequences for women, infants and children in low- and middle-income countries. Soc Sci Med. (2020) 258:113068. doi: 10.1016/j.socscimed.2020.113068

2. Jessel S, Sawyer S, Hernández D. Energy, poverty, and health in climate change: a comprehensive review of an emerging literature. Front Public Health. (2019) 7:357. doi: 10.3389/fpubh.2019.00357

3. Hernández D. Understanding 'energy insecurity' and why it matters to health. Soc Sci Med. (2016) 167:1-10. doi: 10.1016/j.socscimed.2016.08.029

4. Smith KR, Frumkin H, Balakrishnan K, Butler CD, Chafe ZA, Fairlie I, et al. Energy and human health. Annu Rev Public Health. (2013) 34:15988. doi: 10.1146/annurev-publhealth-031912-114404

5. WHO. Overview of Public Health and Social Measures in the Context of COVID-19 (Interim Guidance). Geneva: World Health Organization (2020). Available online at: https://www.who.int/publications/i/item/overview-ofpublic-health-and-social-measures-in-the-context-of-covid-19 (accessed August 29, 2020).

6. Glassman A, Chalkidou K, Sullivan R. Does one size fit all? Realistic alternatives for COVID-19 response in low-income countries. Center Global Dev. (2020) 9. Available online at: https://www.cgdev.org/blog/does-onesize-fit-all-realistic-alternatives-covid-19-response-low-income-countries (accessed August 15, 2020).

7. Nkengasong JN, Ndembi N, Tshangela A, Raji T. COVID19 vaccines: how to ensure Africa has access. Nature. (2020) 586:197-9. doi: 10.1038/d41586-020-02774-8

8. Roda WC, Varughese MB, Han D, Li MY. Why is it difficult to accurately predict the COVID-19 epidemic? Infect Dis Model. (2020) 5:27181. doi: 10.1016/j.idm.2020.03.001

9. WHO. WHO COVID-19 Preparedness and Response Progress Report. Geneva: World Health Organization (2020). Available online at: https://www.who.int/ publications/m/item/who-covid-19-preparedness-and-response-progressreport---1-february-to-30-june-2020 (accessed August 29, 2020).

10. Pillay AL, Barnes BR. Psychology and COVID-19: impacts, themes and way forward. South Afr J Psychol. (2020) 50:14853. doi: 10.1177/0081246320937684

11. Doku DT, Boateng GO, Enyan NIE, Owusu SA, Abor I, Kodom RV, et al. Prevalence and changes in boredom, anxiety and well-being among Ghanaians during the COVID-19 crisis and lockdown: a population-based study. PLoS ONE. (2021)

\section{AUTHOR CONTRIBUTIONS}

GB conceptualized, wrote, and revised the manuscript. LP, LS, and FA contributed to writing and critical revision of the manuscript. All authors approved the final version of the manuscript for publication.

\section{FUNDING}

This work was supported by a start-up grant GB received from the College of Nursing and Health Innovations, The University of Texas at Arlington, Arlington, Texas.

\section{ACKNOWLEDGMENTS}

The content is solely the responsibility of the authors and does not represent the official views of The University of Texas at Arlington.

12. International Energy Agency (IEA). World Energy Outlook 2020. (2020) Available online at: https://www.iea.org/reports/world-energy-outlook-2020 (accessed November 25, 2020).

13. International Energy Agency. Energy Access Outlook 2017: From Poverty to Prosperity. Paris: IEA (2017). Available online at: https://www.iea.org/reports/ energy-access-outlook-2017

14. Beech P. The COVID-19 Pandemic Could Have Huge Knock-on Effects on Women's Health, Says the UN. World Economic Forum (2020). Available online at: https://www.weforum.org/agenda/2020/04/covid-19-coronaviruspandemic-hit-women-harder-than-men/ (accessed December 4, 2020).

15. Simkovich SM, Goodman D, Roa C, Crocker ME, Gianella GE, Kirenga BJ, et al. The health and social implications of household air pollution and respiratory diseases. NPJ Primary Care Respir Med. (2019) 29:117. doi: 10.1038/s41533-019-0126-x

16. UNECA. ECA Report: COVID-19 in Africa: Protecting Lives and Economies. United Nations Economic Commission for Africa (2020). Available online at: https:/www.un.org/africarenewal/news/coronavirus/eca-reportcovid-19-africa-protecting-lives-and-economies (accessed December 26, 2020).

17. Hernández D, Phillips D, Siegel EL. Exploring the housing and household energy pathways to stress: a mixed methods study. Int J Environ Res Public Health. (2016) 13:916. doi: 10.3390/ijerph13090916

18. Ahmad K, Erqou S, Shah N, Nazir U, Morrison AR, Choudhary $\mathrm{G}$, et al. Association of poor housing conditions with COVID-19 incidence and mortality across US counties. PLOS ONE. (2020) 15:e0241327. doi: 10.1371/journal.pone.0241327

19. Widerynski S, Schramm P, Conlon K, Noe R, Grossman E, Hawkins M, et al. The Use of Cooling Centers to Prevent Heat-Related Illness: Summary of Evidence and Strategies for Implementation. Centers for Disease Control and Prevention (2017). Available online at: https://stacks.cdc.gov/view/cdc/47657 (accessed December 4, 2020).

20. Daanen H, Bose-O'Reilly S, Brearley M, Flouris DA, Gerrett NM, Huynen $M$, et al. COVID-19 and thermoregulation-related problems: practical recommendations. Temperature. (2020) 1-11. doi: 10.1080/23328940.2020.179 0971

21. Mendenhall E, Kohrt BA, Norris SA, Ndetei D, Prabhakaran D. Non-communicable disease syndemics: poverty, depression, and diabetes among low-income populations. Lancet. (2017) 389:951-63. doi: 10.1016/S0140-6736(17)30 402-6 
22. Sonego M, Pellegrin MC, Becker G, Lazzerini M. Risk factors for mortality from acute lower respiratory infections (ALRI) in children under five years of age in low and middle-income countries: a systematic review and meta-analysis of observational studies. PLOS ONE. (2015) 10:e0116380. doi: 10.1371/journal.pone.0116380

23. Campbell R. Home Fires Involving Heating Equipment. National Fire Protection Association (2018). Available online at: https://www.nfpa. org//-/media/Files/News-and-Research/Fire-statistics-and-reports/US-FireProblem/Fire-causes/osHeating.pdf

24. Graff M, Carley S. COVID-19 assistance needs to target energy insecurity. Nat Energy. (2020) 5:352-4. doi: 10.1038/s41560-020-0620-y

25. International Energy Agency. Africa and Covid-19: Economic Recovery ad Electricity Access Go Hand in Hand - Analysis. (2020). Available online at: https://www.iea.org/commentaries/africa-and-covid-19-economicrecovery-and-electricity-access-go-hand-in-hand (accessed December 26, 2020).
26. Dahab $M$, van Zandvoort $K$, Flasche $S$, Warsame A, Ratnayake $R$, Favas C, et al. COVID-19 control in low-income settings and displaced populations: what can realistically be done? Confl Health. (2020) 14:54. doi: 10.1186/s13031-020-00296-8

Conflict of Interest: The authors declare that the research was conducted in the absence of any commercial or financial relationships that could be construed as a potential conflict of interest.

Copyright (C) 2021 Boateng, Phipps, Smith and Armah. This is an open-access article distributed under the terms of the Creative Commons Attribution License (CC BY). The use, distribution or reproduction in other forums is permitted, provided the original author(s) and the copyright owner(s) are credited and that the original publication in this journal is cited, in accordance with accepted academic practice. No use, distribution or reproduction is permitted which does not comply with these terms. 